\title{
Preparation, characterization, and evaluation of antitumor effect of Brucea javanica oil cationic nanoemulsions
}

This article was published in the following Dove Press journal:

International Journal of Nanomedicine

2 June 2016

Number of times this article has been viewed

Ting-ting Liul-3

$\mathrm{Li}-\mathrm{Qiu} \mathrm{Mu}^{\mathrm{I}-3}$

Wei Dai ${ }^{1-3}$

Chuan-bang Wang ${ }^{1-3}$

Xin-Yi Liu' ${ }^{1-3}$

Da-Xiong Xiang ${ }^{1-3}$

'Department of Pharmacy, The Second Xiangya Hospital, ${ }^{2}$ Institute of Clinical Pharmacy, Central South University, ${ }^{3}$ Key Laboratory for New Technology of Chinese Medicine Preparations of Hunan Province, Changsha, People's Republic of China
Correspondence: Da-Xiong Xiang The Second Xiangya Hospital of Central South University, No 139 Middle Renmin Road, Changsha, Hunan 4I00II, People's Republic of China Tel +86 73I 85292129 Email xiangdaxiong@।63.com
Abstract: The purpose of this study was to prepare Brucea javanica oil cationic nanoemulsions (BJO-CN) with BJO as drug as well as oil phase and chitosan as cationic inducer, to explore the practical suitability of using cationic nanoemulsions for oral delivery of mixed oil, and to test its bioavailability and antitumor effect. BJO-CN was prepared by chitosan solution stirring method and then characterized physicochemically. The obtained BJO-CN had a spherical morphology with a positive zeta potential of $18.9 \mathrm{mV}$ and an average particle size of $42.36 \mathrm{~nm}$, showing high colloidal stability. The drug loading of BJO-CN was $91.83 \mathrm{mg} \cdot \mathrm{mL}^{-1}$, determined by highperformance liquid chromatography with precolumn derivatization. Pharmacokinetic studies revealed that, compared with BJO emulsion (BJO-E) (the dosage of BJO-CN and BJO-E was equal to $505 \mathrm{mg} \cdot \mathrm{kg}^{-1}$, calculated by oleic acid), BJO-CN exhibited a significant increase in the area under the plasma drug concentration-time curve over the period of 24 hours and relative bioavailability was 1.6-fold. Furthermore, the antitumor effect of $\mathrm{BJO}-\mathrm{CN}$ in the orthotopic mouse model of lung cancer was evaluated by recording the median survival time and the weight of lung tissue with tumor, hematoxylin and eosin staining, and immunohistochemical technique. Results of anticancer experiments illustrated that, even though the administrated dosage in the BJO-CN group was half of that in the BJO-E group, BJO-CN exhibited similar antitumor effect to BJO-E. Moreover, BJO-CN had good synergistic effect in combination therapy with vinorelbine. These results suggested that cationic nanoemulsions are an effective and promising delivery system to enhance the oral bioavailability and anticancer effect of BJO.

Keywords: oleic acid, chitosan, combined chemotherapy, orthotopic mouse model of lung cancer, pharmacokinetics

\section{Introduction}

Lung cancer is one of the most common malignant tumors showing a rising trend of incidence in recent years, with $80 \%$ of patients suffering from non-small-cell lung cancer. Because the disease has no early significant symptoms, it is usually diagnosed as an advanced stage malignant tumor and is treated with a chemotherapy regimen. Chemotherapy for curing advanced non-small-cell lung cancer is usually a kind of combined treatment, such as the association of paclitaxel and cisplatin, which could achieve better therapeutic effect, but is often accompanied with greater toxicity and more side effects. Besides, considering that the patients suffering from terminal cancer are relatively weak, they have poor tolerance to chemotherapy, which easily leads to interruption in the course of treatment. Thus, there is a need to improve the treatment strategy to one which can not only kill cancer but also reduce the side effects of chemotherapy, thus improving patients' quality of life. submit your manuscript Dovepress $5 \%$ in 6 http://dx.doi.org/10.2147uj,s101918 cc) ${ }_{\mathrm{BY}} \mathrm{NC}$ and incorporate the Creative Commons Attribution - Non Commercial (unported, v3.0) License (http://creativecommons.org/licenses/by-n/3.0/). By accessing the work you hereby accept the Terms. Non-commercial uses of the work are permitted without any further permission from Dove Medical Press Limited, provided the work is properly attributed. For permission for commercial use of this work, please see paragraphs 4.2 and 5 of our Terms (https://www.dovepress.com/terms.php). 
Brucea javanica oil (BJO) is an extract of the ripe fruit of the simaroubaceae plant Brucea javanica (L.) Merr. and is a traditional Chinese medicine in the national protection system, mainly produced in the People's Republic of China's coastal tropical and subtropical regions such as Hainan, Guangdong, Guangxi, Yunnan, and other places. ${ }^{1}$ BJO is a mixed fatty oil, mainly composed of triolein, saturated and unsaturated fatty acids (such as oleic acid, linoleic acid, and stearic acid), and triterpenoid alcohols (such as taraxerol, euphorbia dienol, lupeol, $\beta$-amyrin, and $\alpha$-amyrin). ${ }^{2}$ Oleic and linoleic acids in $\mathrm{BJO}$ are the main active ingredients for the antitumor activity (the total acid content in refined BJO is $>95 \%),{ }^{3}$ and conjugated fatty acid can be metabolized to free fatty acids - oleic acid, producing effect in the body., Many studies have shown that BJO has a variety of pharmacological activities, including anti-HIV (human immunodeficiency virus), antimalarial, antituberculosis, cytotoxic, and antitumor activities. ${ }^{6}$ BJO exerts antitumor effect in many ways: ${ }^{7} 1$ ) affect tumor cell cycle and kill tumor cells of $\mathrm{G}_{0}$, $\mathrm{G}_{1}, \mathrm{~S}, \mathrm{G}_{2}$, and $\mathrm{M}$ phases by inhibiting the synthesis of DNA, RNA, and protein; ${ }^{8} 2$ ) destruct biological structure of tumor cells $\left.;{ }^{9} 3\right)$ activate Caspase- $3^{10}$ and inhibit the expression of NF- $\kappa \mathrm{B},{ }^{11}$ mutant P53, and B-cell lymphoma-2 (Bcl-2); ${ }^{12}$ and 4) reverse multidrug resistance in cancer cells and inhibit the activity of topoisomerase-II. ${ }^{13,14}$ In addition, BJO can protect normal bone marrow and increase the number of white blood cells, promoting the body's immune system. ${ }^{15}$

At present, there are several kinds of $\mathrm{BJO}$ products in the market available as oral emulsion, ${ }^{16,17}$ injectable emulsion, ${ }^{18}$ as well as soft capsules, mainly used for clinical adjuvant therapy of lung cancer and lung cancer with brain metastasis. ${ }^{19}$ When combined with chemotherapy in the treatment for advanced non-small-cell lung cancer, BJO can not only play a synergistic effect but also significantly improve the clinical symptoms and life quality of patients by reducing the toxicity and side effects induced by chemotherapy. ${ }^{20,21}$ Many clinical observations have confirmed that BJO is suitable for clinical promotion and worthy of direct reference. ${ }^{22}$ However, the current BJO preparations available in the market are frequently administrated with large dosage (oral emulsion: $2 \mathrm{~mL} \mathrm{BJO} / 20 \mathrm{~mL}, 20 \mathrm{~mL} /$ time, two to three times/ day; soft capsule: $0.5 \mathrm{~mL} /$ capsule, four capsules/time, two to three times/day [according to the 2015 version of Chinese Pharmacopoeia]). Besides, their poor taste causes nausea, vomiting, and other gastrointestinal effects in patients. ${ }^{18,21}$ Therefore, it is necessary to develop a new type of oral preparation to improve the antitumor effect of BJO and reduce its dosage and frequency for oral administration.
Nanoemulsions are thermodynamically stable systems consisting of oil phase, water phase, and a surfactant, often with a cosurfactant. ${ }^{23}$ Conventional nanoemulsions are usually negatively charged and can be transformed into cationic nanoemulsions by adding a cationic inducer such as chitosan, oil amine, and stearic amine. ${ }^{24}$ Cationic nanoemulsions possess the inherent advantages of nanoemulsions such as simple preparation, improved solubility and bioavailability of hydrophobic drugs, sustained release, and target effect. ${ }^{23}$ Besides, cationic nanoemulsions have better stability during the course of preparation evaluation and at cationic physiological environment, which is because there exists electrostatic repulsion between cationic nanoemulsion particles with other positively charged surface. Some literatures have reported that cationic nanoemulsions can not only improve the permeability of poor water-soluble drugs ${ }^{25}$ but also form complexes with macromolecular drugs (containing functional groups with a large number of negatively charge), such as nucleic acids, proteins, and other large molecules, to protect them from enzyme degradation and improve their absorption. ${ }^{26}$ The absorption mechanism is probably that cationic particles have electrostatic interaction and mucosal adhesion with negatively charged membrane of the contacted organs, such as skin, ${ }^{27,28}$ eyes, ${ }^{26,29}$ and gastrointestinal mucosa, ${ }^{30,31}$ to improve drugs' retention and permeability. ${ }^{26,30}$ Chitosan is a kind of cationic alkaline polysaccharide extracted from crustaceans and is widely used in biomedical engineering with good biocompatibility and biodegradability. It has been reported that on the application of chitosan in oral formulations, it binds to negatively charged sialic acid on the surface of the intestinal mucosa, thereby improving the adhesion of nanoemulsions particles and extending the residence time of drugs on absorption sites..$^{30,32,33}$ In addition, protonated chitosan could interact with negatively charged serine of proteins on intestinal cell membrane, and then reversibly regulate F-actin and tight junction proteins among intercellular spaces, thereby opening tight junctions and promoting paracellular transport of drugs. ${ }^{34,35}$ Therefore, we first planned to prepare stable BJO-loaded and chitosan-modified cationic nanoemulsions and then study its pharmacokinetic profile and antitumor effect in the orthotopic mouse model of lung cancer to achieve better therapeutic effect of BJO and more extensive application in clinic.

\section{Materials and methods}

BJO was purchased from Jiangxi Tianli Pharmaceutical Co., Ltd (Jiangxi, People's Republic of China), and the same batch of BJO was used throughout the study. BJO emulsion 
(BJO-E) was purchased from Shenyang Pharmaceutical Co., Ltd (Liaoning, People's Republic of China). Cremophor RH40 was purchased from Shanghai Yunhong Chemical Co., Ltd (Shanghai, People's Republic of China). Plurol Oleique CC497 (Plu) was kindly gifted by BASF SE (Ludwigshafen, Germany). Chitosan was purchased from Shanghai Qibang Industrial Co., Ltd (Shanghai, People's Republic of China). Glacial acetic acid was purchased from Sinopharm Chemical Regent Co., Ltd (Beijing, People's Republic of China). All other chemicals and reagents used in this study were of analytical grade and were obtained commercially.

Human pulmonary adenocarcinoma A549 cells were purchased from the Cell Bank of Academy of Science (Shanghai, People's Republic of China). Fetal bovine serum, RPMI-1640 medium, and 0.05\% trypsin were purchased from Hanyang Biotechnology Co., Ltd (Tianjin, People's Republic of China). A total of $100 \mathrm{U} / \mathrm{mL}$ of penicillin and $100 \mathrm{mg} / \mathrm{mL}$ of streptomycin were bought from Abnova (Irvine, CA, USA). BALB/c female nude mice (weight:

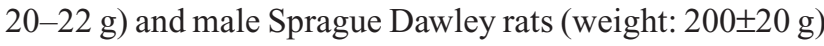
were supplied by the Second Xiangya Hospital of Central South University (Hunan, People's Republic of China). All the cell and animal studies were approved by the Ethics Committee in the Experimental Animal Center of the Second Xiangya Hospital and were in compliance with the National Institutes of Health Guide for Care and Use of Laboratory Animals.

\section{Preparation of $\mathrm{BJO}$ cationic nanoemulsions}

$\mathrm{BJO}$ acted as an effective ingredient as well as the oil phase in the preparation of BJO cationic nanoemulsions (BJO-CN). A pseudoternary phase diagram was constructed to form nanoemulsions. The existence of the nanoemulsion region within the diagrams was observed visually. Variable proportions of oil, surfactant, and cosurfactant were mixed in a glass vial at ambient temperature until they were completely blended. Then, $1 \%$ acetic acid aqueous solution (containing $0.75 \%$ chitosan) was added to the mixture solution drop by drop under magnetic stirring until a transparent liquid with blue opalescence was obtained, which was BJO-loaded and CS-modified cationic nanoemulsion.

\section{Determination of oleic acid in BJO-CN}

The concentration of oleic acid in BJO-CN was determined using a high performance liquid chromatography (HPLC) system (Shimadzu LC-20AT, Kyoto, Japan) with the precolumn derivation method. Chromatographic separation was conducted on a Welchrom ${ }^{\circledR} \mathrm{C} 18$ column (Welch Materials, Shanghai, People's Republic of China) $(4.6 \times 250 \mathrm{~nm}, 5 \mu \mathrm{m})$. The mobile phase consisted of a mixture of methanol (A) and acetonitrile (B) delivered as gradient elution (0.00-8.00, 85\% A; 8.00-9.00, 85\%-95\% A; 9.00-12.00, 95\% A; 12.00 $13.00,95 \%-100 \%$ A; $13.00-14.00,100 \%$ A; 14.00-15.00, 100\%-85\% A; 15.00-20.00, 85\% A), which was delivered at an isocratic flow rate of $1 \mathrm{~mL} \cdot \mathrm{min}^{-1}$ at $40^{\circ} \mathrm{C}$. The injection volume was $10 \mu \mathrm{L}$, and the detection wavelength was set at $242 \mathrm{~nm}$.

\section{Physicochemical characterization of BJO-CN}

BJO-CN were diluted 50 times and mixed by gentle shaking. Then, both its size distribution and zeta potential were determined using the Zetasizer NanoZS90 instrument (Malvern Instruments, Malvern, UK). The morphology of BJO-CN was observed under a transmission electron microscope (TEM; JEM-1230; JEOL, Tokyo, Japan). One drop of diluted sample was deposited on the copper grid covered with carbon film and the excess liquid was absorbed with a filter paper. After the diluent was dried, the TEM analysis was performed.

\section{Stability of BJO-CN}

The stability of BJO-CN was tested in artificial gastric juice and intestinal juice, which simulated the influence of gastrointestinal tract on the characteristics of BJO-CN in vivo. Artificial gastric juice and intestinal juice were prepared according to the "Chinese Pharmacopoeia" (2010 version). Freshly prepared BJO-CN were incubated for 1 hour in a certain amount of artificial gastric juice and intestinal juice, respectively, with a dilution ratio of $1: 15$, as determined by a preliminary experiment. Then, after centrifugation at 13,000 rpm for 5 minutes, the supernatant was assessed for size distribution and polydispersity index (PDI) using the Malvern laser analyzer (Malvern Instruments). Besides, in order to study the stability of BJO-CN, three independent batches of BJO-CN were stored respectively at $4{ }^{\circ} \mathrm{C}$ and $25^{\circ} \mathrm{C}$ for 60 days. Samples were observed for appearance and assessed for size distribution on the days $7,15,30$, and 60 .

\section{Pharmacokinetic studies in rats}

Twenty male Sprague Dawley rats that were fasted overnight but had free access to water before oral administration were randomly divided into three groups: blank control group ( $n=8$, treated with $0.9 \%$ saline), reference group $(n=6$, treated with $\left.6.0 \mathrm{~mL} \cdot \mathrm{kg}^{-1}, \mathrm{BJO}-\mathrm{E}\right)$, and test group $(\mathrm{n}=6$, treated with $\left.5.2 \mathrm{~mL} \cdot \mathrm{kg}^{-1}, \mathrm{BJO}-\mathrm{CN}\right)$. The administered drug content 
of BJO-CN and BJO-E group was equal to $505 \mathrm{mg} \cdot \mathrm{kg}^{-1}$ (calculated by oleic acid). Blood samples were collected from retro-orbital plexus of rats at designated time points and centrifuged to obtain plasma. cis-10-Heptadecenoic acid solution $\left(244.3 \mu \mathrm{g} \cdot \mathrm{mL}^{-1}, 15 \mu \mathrm{L}\right)$ and sodium hydroxide solution $\left(2.0 \mathrm{~mol} \mathrm{~L}^{-1}, 100 \mu \mathrm{L}\right)$ were added to the plasma and mixed for 3 minutes. The mixture was heated at $60^{\circ} \mathrm{C}$ for 1.5 hours and then cooled to room temperature. Afterward, $15 \mu \mathrm{L}$ of methanoic acid and $150 \mu \mathrm{L}$ of acetone were added to the above solution and mixed for 3 minutes; the solution was then centrifuged at 13,000 rpm for 10 minutes, and $200 \mu \mathrm{L}$ of the supernatant was transferred into a $300 \mu \mathrm{L}$ preinserted vial for ultra performance liquid chromatography-tandem mass spectrometer (UPLC-MS/MS) analysis.

UPLC-MS/MS (Ultra performance liquid chromatography system, SHIMADZU LC-20AT, Kyoto, Japan/ Mass spectrometer of compounding type with tandem triple quadrupole - linear ion hydrazine, Applied Biosystems 4000 QTRAP, USA) was used to analyze the concentration of oleic acid in blood samples. Chromatographic separation was conducted on a BEH C18 column $(2.1 \times 50 \mathrm{~mm}, 1.7 \mu \mathrm{m}$, Waters, Milford, MA, USA). The mobile phase was composed of $0.1 \%$ methanoic acid (as eluent $A$ ) and methanol (as eluent B), with the ratio of eluent $\mathrm{A}$ :eluent $\mathrm{B}=7: 93$, vol $/ \mathrm{vol}$, which was delivered at an isocratic flow rate of $0.2 \mathrm{~mL} \cdot \mathrm{min}^{-1}$ at $40^{\circ} \mathrm{C}$. The Quattro was operated in ESI negative mode, and the source temperature was $120^{\circ} \mathrm{C}$. Besides, capillary voltage was set at $3.8 \mathrm{kV}$, and cone voltage was $45 \mathrm{~V}$.

\section{Antitumor effect study}

\section{Establishment of orthotopic mouse model of lung cancer and experimental grouping}

The orthotopic mouse model of lung cancer was established following previously published studies. ${ }^{36-39}$ Human pulmonary adenocarcinoma A549 cell was cultured in RPMI-1640 medium containing $10 \%$ ( $\mathrm{vol} / \mathrm{vol})$ heat-inactived fetal bovine serum at $37^{\circ} \mathrm{C}$ in $5 \% \mathrm{CO}_{2}$ and routinely subcultured every 3 days. The cells grown to subconfluence were harvested with $0.1 \%$ trypsin, washed twice with phosphate-buffered saline, and resuspended in phosphate-buffered saline. The concentration of cells was adjusted to $4 \times 10^{7} \mathrm{~mL}^{-1}$ and mix $50 \mu \mathrm{L}$ of cell suspension $\left(2 \times 10^{6}\right.$ cells $)$ was mixed with $50 \mu \mathrm{L}$ of Matrigel $^{\circledR}$ (BD Biosciences, San Jose, CA, USA) for intrapulmonary cell implantation. Female BALB/c nude mice at 4 weeks were housed and fed for 7 days to help them adapt to the environment. The mice were intraperitoneally injected with $10 \%$ aquachloral $\left(2.5 \mathrm{~mL} \cdot \mathrm{kg}^{-1}\right)$ to induce anesthesia and fixed in the right decubitus position. Then, $100 \mu \mathrm{L}$ of cell suspension (containing $2 \times 10^{6}$ cells) was percutaneously inoculated between the fourth and fifth rib space on the left anterior axillary line to the depth of $\sim 5 \mathrm{~mm}$ rapidly. The injector was quickly removed after the injection of cell suspension. Then, the mouse was turned to the left decubitus position, and animals were observed for $\sim 60$ minutes until full recovery. Eighteen days postimplantation, a spiral computed tomography (CT) (Aquilion16-slice CT scanner, Toshiba, Tokyo, Japan) scanner was used to observe the intrathoracic tumor formation.

Successful model mice were randomly divided into five groups (six mice per group): model group (0.9\% saline), positive group $\left(14.05 \mathrm{mg} \cdot \mathrm{kg}^{-1} \cdot \mathrm{wk}^{-1}\right.$, vinorelbine tartrate $[\mathrm{VbT}])$, reference group $\left(8.65 \mathrm{~mL} \cdot \mathrm{kg}^{-1} \cdot \mathrm{d}^{-1}, \mathrm{BJO}-\mathrm{E}\right)$, test group $\left(3.75 \mathrm{~mL} \cdot \mathrm{kg}^{-1} \cdot \mathrm{d}^{-1}, \mathrm{BJO}-\mathrm{CN}\right)$, and combination group (14.05 $\mathrm{mg} \cdot \mathrm{kg}^{-1} \cdot \mathrm{wk}^{-1} \mathrm{VbT}$ and $3.75 \mathrm{~mL} \cdot \mathrm{kg}^{-1} \cdot \mathrm{d}^{-1} \mathrm{BJO}-\mathrm{CN}$ ). Because BJO preparations are primarily combined with front-line anticancer drugs for adjuvant therapy clinically, we set up the positive control and the combination group. The administered drug content in the BJO-E group was twice that in the BJO-CN group (calculated by oleic acid). BJO-CN and BJO-E were given by intragastric gavage to the mice once a day for 28 days. The VbT solution was given by gavage to the mice once a week for 28 days.

\section{Determination of antitumor effect}

$\mathrm{BALB} / \mathrm{c}$ nude mice were divided into two groups in parallel for survival detection and pathological experimentation. The mice in the survival group were not killed, they were allowed to die naturally, and those in the pathological group were killed. Survival and death of the mice bearing lung tumor were recorded throughout the administration course. At the end of the treatment, the mice were killed for weighing the lung tissues with tumor. Furthermore, we used hematoxylin and eosin (HE) staining to observe the pathological changes of lung tissues and employed immunohistochemical (IHC) technique to detect the expressions of vascular endothelial growth factor (VEGF), interleukin-8 (IL-8), Bcl-2, and P53 in tumor tissue for confirming the antitumor effect of BJO-CN in the orthotopic lung cancer model. Random images $(400 \times)$ per experiment group were captured using a microscope equipped with the analysis software ImagePro-Plus (MediaCybernetics, Rockville, MD, USA). The semi quantification of protein expression was determined by analyzing the mean integrated optical density (IOD) in a randomly selected manner. 


\section{Statistic analysis}

All the data were analyzed using SPSS 19.0 (IBM Corporation, Armonk, NY, USA). One-way analysis of variance with least significant difference test was used to analyze the weight of lung tissues with tumor and IOD. Statistical differences were considered significant when $P<0.05$.

\section{Results and discussion Preparation of BJO-CN}

$\mathrm{BJO}$ is a kind of mixed fatty acid that is used as the oil phase in the study. To obtain transparent nanoemulsions with good stability, it was necessary to optimize surfactants, cosurfactants, and the proportion of all the ingredients. Because BJO could not be matched with any of the surfactants and cosurfactants, we chose a mixture of surfactants to improve the compatibility among each constitution and decrease the amount of surfactants at the same time. Before preparing BJO-CN, we first formulated the BJO nanoemulsions (BJO-N) without chitosan modification. The formulation contained Cremophor RH40 (RH40) and Plurol Oleique CC497 (Plu) as mixed surfactants and glycerin as the cosurfactant. The constructed pseudoternary phase diagrams are shown in Figure 1. A clear and transparent nanoemulsion was identified in the black zone. The optimal nanoemulsion was selected from this area. Based on the results of ternary phase diagrams and combined with the appearance and stability, the selected formulation of BJO-N was the ratio of $\mathrm{RH} 40$, Plu, glycerin, BJO, and water, 11.67:5.83:5.83:10.00:66.67 (m/m/m/m/m). Afterward, we added the chitosan solution to the system to modify BJO-N. Through a preliminary experiment, we found that when the concentration of chitosan in $1 \%$ acetic acid solution was $0.75 \%$, the zeta potential reached its maximum. Then, the distilled water in BJO-N was replaced by the same weight of chitosan solution as the water phase. Therefore, the optimized concentration of BJO-CN was determined, and the $\mathrm{pH}$ of this system was detected to be 4.78 .

\section{Content determination of oleic acid}

According to The Ministry of Health issued Drug Standards (The 14th book of Chinese Medicine Prescription Preparations) regulations, the total amount of refined BJO is not less than $95.0 \%$ (calculated by oleic acid), so oleic acid is usually used as detection indicator to determine the drug content of BJO-CN. Many studies have shown that HPLC with precolumn derivatization contributed to the determination of oleic acid in BJO formulations. ${ }^{40,41}$ Results indicated that the content of oleic acid in BJO-CN was $91.83 \mathrm{mg} \cdot \mathrm{mL}^{-1}$.

\section{Physicochemical characterization of BJO-CN}

The particle size distribution and zeta potential are two important factors, affecting the stability of cationic nanoemulsions. The average particle size of BJO-CN was $42.36 \mathrm{~nm}$, with a PDI value of 0.091. The smaller the size of the particles, the slower the particles float or sink. The aggregation of particles was reduced significantly because of uniform particle size distribution (PDI <0.2). ${ }^{42}$ The zeta potential of BJO-CN was $18.9 \mathrm{mV}$. The optimum range of zeta potential in cationic nanoemulsions is $20-40 \mathrm{mV}$. When the value is $<10 \mathrm{mV}$, the system will be less stable and flocculation or layer appear during the later steam sterilization. ${ }^{29}$ In addition, we made a comparison in terms of particle size and zeta potential between BJO-CN and BJO-N. Results showed that there was a slight increase in the average particle size from $36.33 \mathrm{~nm}$ of BJO-N (with PDI value of 0.078 ) to $42.36 \mathrm{~nm}$ of BJO-CN, with a significant reversion of zeta potential from $-4 \mathrm{mV}$ of BJO-N to $18.9 \mathrm{mV}$ of BJO-CN, demonstrating that protonated chitosan molecules may be coated on the surface of particles when its acetic acid solution was added into nanoemulsions as the water phase. The TEM result (Figure 2) demonstrated that the particles of BJO-CN were spherical and had uniform size. However, the particle size measured using TEM was slightly smaller than that measured using Malvern laser particle size analyzer, which was probably caused by different detection principles between the two machines. For example, TEM and dynamic light scattering focus on the average length and average volume of particles, respectively, so the calculated results are different. Besides, the particle size measured by dynamic light scattering contains the thickness of hydration layer outside the particle, while dried sample is detected by TEM without the hydration layer.

\section{Stability of BJO-CN}

The changes in the particle size of BJO-CN in the artificial gastric juice and intestinal juice are listed in Table 1. Results indicate that the artificial gastric juice and intestinal juice had very little effect on the particle size distribution of BJO-CN. The effect of temperature on particle size and zeta potential of samples are shown in Figures 3 and 4, respectively, demonstrating that particle size distribution and zeta potential of freshly prepared samples did not change when stored at $4^{\circ} \mathrm{C}$ and $25^{\circ} \mathrm{C}$ for 60 days. In addition, throughout the observation, BJO-CN were always a clear and transparent liquid with bluish opalescence. Results illustrated that 


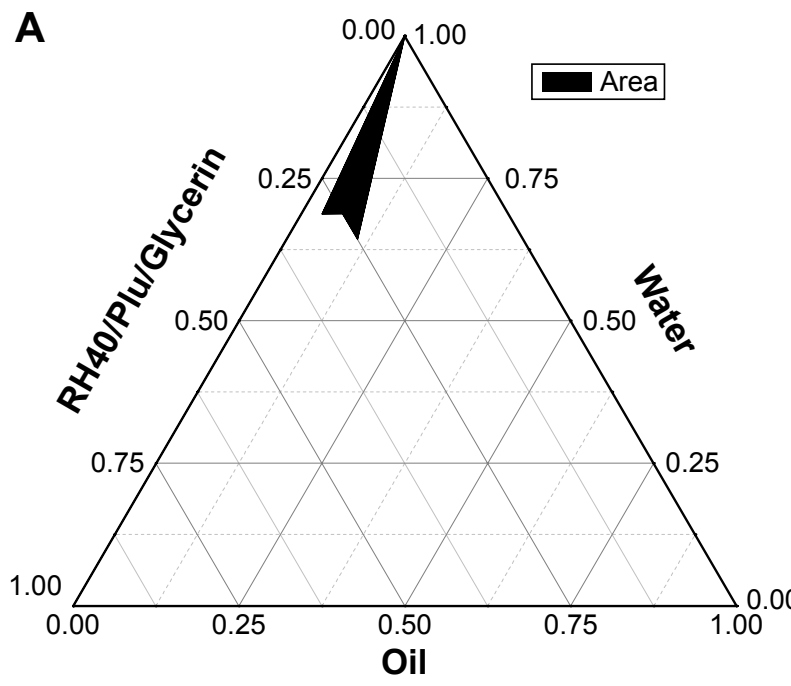

$K_{\mathrm{m}}=3: 1 /$ RH40:Plu $=2: 1$

C

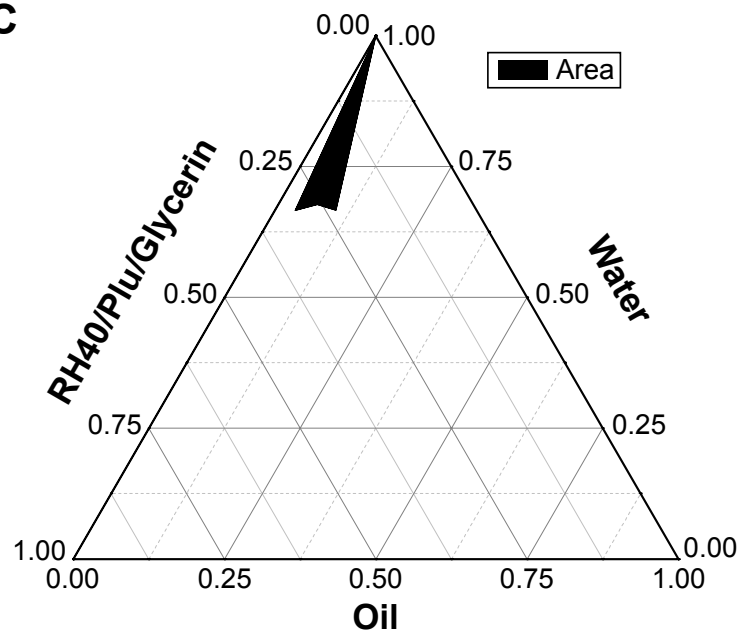

$K_{\mathrm{m}}=3: 2 /$ RH40:Plu $=2: 1$
B

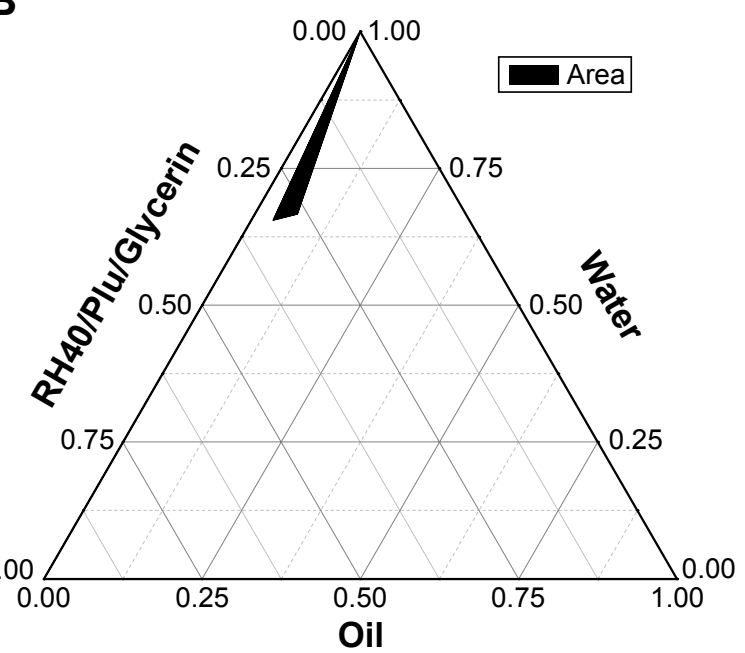

$K_{\mathrm{m}}=3: 1 /$ RH40:Plu $=4: 1$

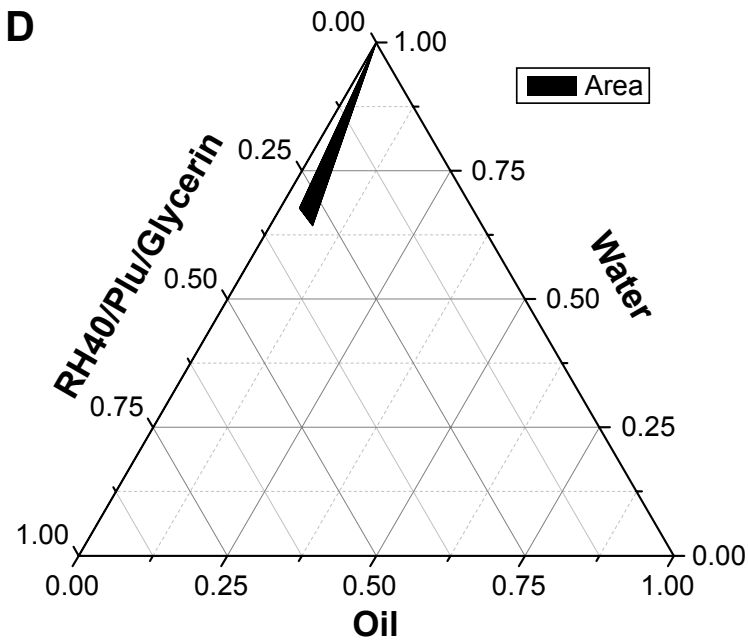

$K_{\mathrm{m}}=2: 1 /$ RH40: $\mathrm{Plu}=4: 1$

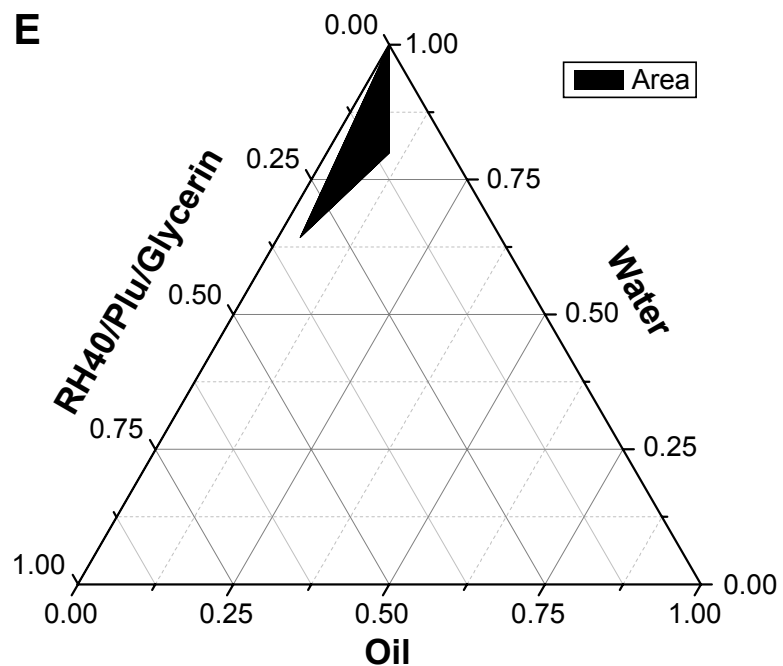

$K_{\mathrm{m}}=1: 1 /$ RH40:Plu $=2: 1$

Figure I The pseudoternary phase diagrams of BJO-N.

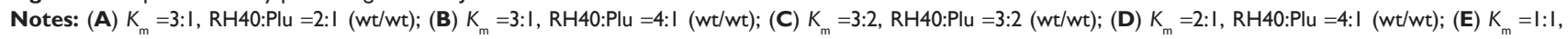
$\mathrm{RH} 40: \mathrm{Plu}=2: \mathrm{I}(\mathrm{wt} / \mathrm{wt})$. BJO was used as the oil phase. The black area represents the nanoemulsion existence range.

Abbreviations: BJO-N, Brucea javanica oil nanoemulsions; $K_{m}$, the weight ratio of surfactant/cosurfactant; $\mathrm{RH} 40$, Cremophor RH40; Plu, Plurol Oleique CC497. 


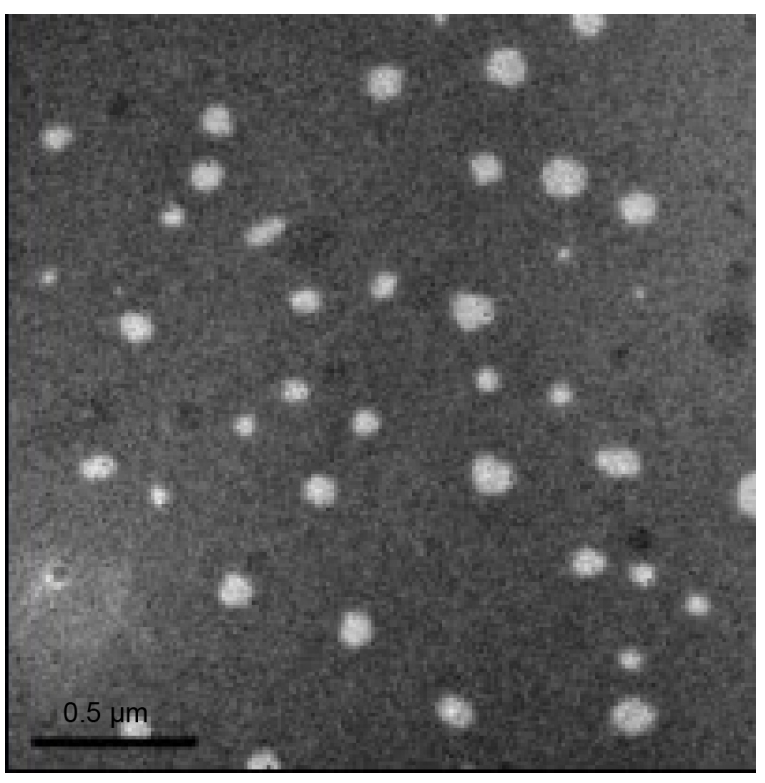

Figure 2 TEM analysis of BJO-CN.

Note: Scale bar: $0.5 \mu \mathrm{m}$.

Abbreviations: BJO-CN, Brucea javanica oil cationic nanoemulsions; TEM, transmission electron microscope.

BJO-CN remained stable when stored at room temperature $\left(25^{\circ} \mathrm{C}\right)$ as well as at low temperature $\left(4^{\circ} \mathrm{C}\right)$ for 2 months. However, it remains to be further investigated whether partial decomposition of chitosan in acidic solution might occur over time, which would affect the long-term stability of BJO-CN.

\section{Pharmacokinetic studies in rats}

The concentration of BJO in blood plasma was determined at various time points in fasting rats after oral administration of a single dose of BJO-E or BJO-CN. Because oleic acids are endogenous long-chain polyunsaturated fatty acids, we first tested the concentration of oleic acid in the rats of the blank control group (Figure 5). The results demonstrated that there was a large change in the amount of oleic acid in rats during 12 hours, ranging from $\sim 80$ to $180 \mu \mathrm{g} \cdot \mathrm{mL}^{-1}$. Related literatures have reported that the content of free fatty acid in fasting rats increases significantly (but fasting has different effect on free fatty acid in each rat), for example, the plasma concentration of oleic acid in rats was $\sim 100 \mu \mathrm{g} \cdot \mathrm{mL}^{-1}$ in the

Table I Stability of BJO-CN in artificial gastric juice and artificial intestinal juice $(n=3)$

\begin{tabular}{llll}
\hline Group & \multicolumn{3}{l}{ Average particle size (nm)/PDI } \\
\cline { 2 - 4 } & Number I & Number 2 & Number 3 \\
\hline Artificial gastric juice & $40.25 / 0.047$ & $40.20 / 0.043$ & $40.15 / 0.047$ \\
Artificial intestinal juice & $40.67 / 0.080$ & $40.64 / 0.069$ & $40.73 / 0.070$ \\
\hline
\end{tabular}

Abbreviations: BJO-CN, Brucea javanica oil cationic nanoemulsions; PDI, polydispersity index.

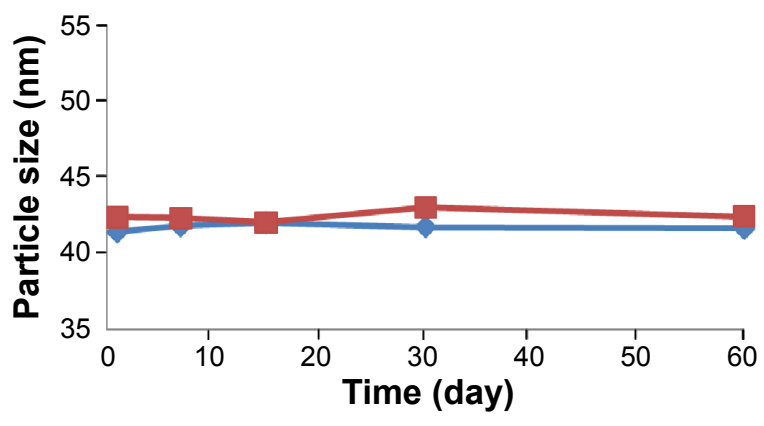

Figure 3 Time-dependent change of particle size in BJO-CN.

Notes: The blue line represents $4^{\circ} \mathrm{C}$; the red line represents $25^{\circ} \mathrm{C}(\mathrm{n}=3)$.

Abbreviation: BJO-CN, Brucea javanica oil cationic nanoemulsions.

morning, ${ }^{43,44}$ which is consistent with the results obtained in this experiment. Because there was a large amount of oleic acid in the fasting rats affecting the determination of oleic acid from the external source, we used the difference in value of oleic acid between the administration group and the blank group as the absorption of exogenous oleic acid ${ }^{3}$ (as shown in Figure 6) and then calculated the related pharmacokinetic parameters (as listed in Table 2). Results indicated that compared with the $\mathrm{BJO}-\mathrm{E}, \mathrm{AUC}_{0 \rightarrow \infty}$ of $\mathrm{BJO}-\mathrm{CN}$ significantly increased and that the relative bioavailability of $\mathrm{BJO}-\mathrm{CN}$ to BJO-E was 1.6 times. Besides, $t_{1 / 2}$ also extended accordingly, illustrating that cationic nanoemulsions as drug delivery carrier significantly promoted the absorption of BJO in the gastrointestinal tract. Apart from this, multimodal phenomenon appeared in the plasma concentration-time curves of BJO-CN and BJO-E. We speculated that the possible reasons are as follows. First, BJO contains not only free fatty acid but also oleic acid glycerides, leading to absorption in many ways in rats after oral administration. ${ }^{45}$ Second, as oleic acids are endogenous long-chain polyunsaturated fatty acids, there exists great possibility for enterohepatic circulation. Third, oleic acid has strong liposolubility, which makes it easy to be stored in the intestinal cells and liver cells or enriched by

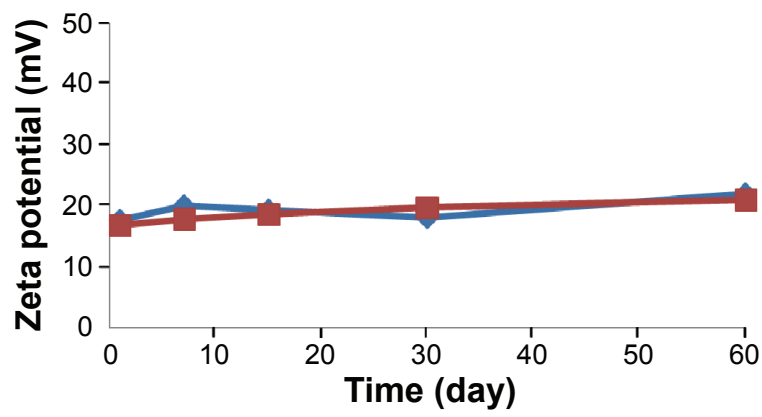

Figure 4 Time-dependent change of zeta potential in BJO-CN.

Notes: The blue line represents $4^{\circ} \mathrm{C}$; the red line represents $25^{\circ} \mathrm{C}(\mathrm{n}=3)$.

Abbreviation: BJO-CN, Brucea javanica oil cationic nanoemulsions. 


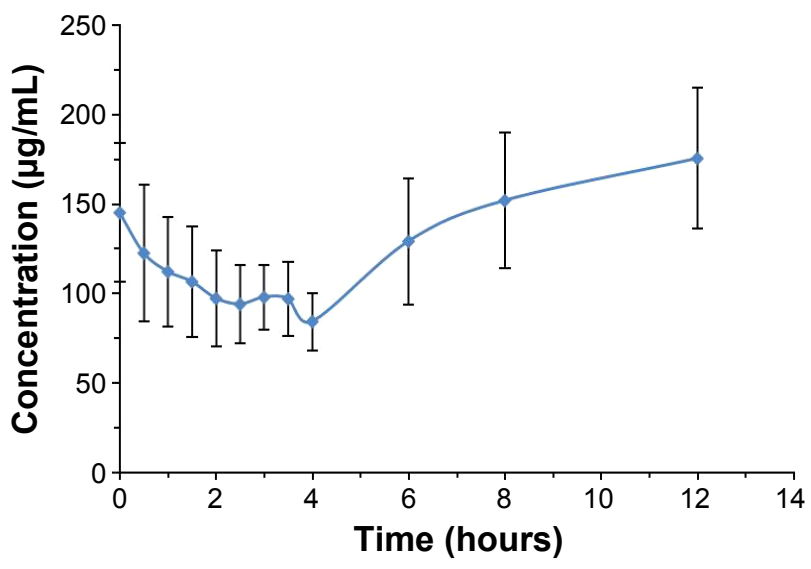

Figure 5 Plasma concentration-time profiles of oleic acid in rats of the blank control group $(\mathrm{n}=8, \bar{x} \pm \mathrm{s})$.

Abbreviation: s, standard deviation.

reticular epithelial tissue. However, all the above conjectures need to be further verified.

\section{Antitumor effect study}

Establishment of orthotopic mouse model of lung cancer

After transplanting human lung adenocarcinoma A549 cell into the chest of nude mice, no distinct pathological features appeared, and nude mice had normal diet and activities. However, because tumor cells were directly injected into the chest of nude mice, the growth of lung tumor could not be conveniently observed. Therefore, we employed a clinical CT scanner to detect the formation of tumors by imaging evaluation of the nude mice. As A549 human lung adenocarcinoma cell proliferated slowly at the early stage, ${ }^{46}$ we randomly chose 20 nude mice for imaging evaluation on the

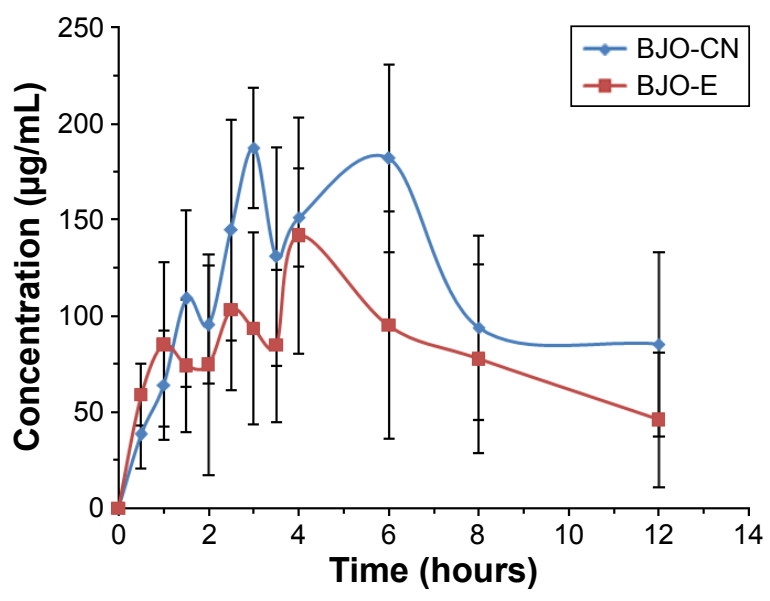

Figure 6 Plasma concentration-time profiles of oleic acid in rats after oral single administration with BJO-CN, BJO-E ( $n=6, \bar{x} \pm s)$.

Abbreviations: BJO-CN, Brucea javanica oil cationic nanoemulsions; BJO-E, Brucea javanica oil emulsion; s, standard deviation.
Table 2 Pharmacokinetic parameters of BJO-CN and BJO-E following oral administration of $505 \mathrm{mg} \cdot \mathrm{kg}^{-1} \mathrm{BJO}$ to rats

\begin{tabular}{lll}
\hline Pharmacokinetic parameters & BJO-CN & BJO-E \\
\hline $\mathrm{AUC}_{0 \rightarrow 12}\left(\mathrm{mg} \cdot \mathrm{h} \cdot \mathrm{L}^{-1}\right)$ & $\mathrm{I}, 203.4 \pm 433.9$ & $982.5 \pm 349.5$ \\
$\mathrm{AUC} \mathrm{O}_{0 \rightarrow \infty}\left(\mathrm{mg} \cdot \mathrm{h} \cdot \mathrm{L}^{-1}\right)$ & $\mathrm{I}, 768.2 \pm 104.0^{*}$ & $\mathrm{I}, 103.8 \pm 425.7$ \\
$T_{\text {max }}(\mathrm{h})$ & $3.5 \pm \mathrm{I} .4$ & $3.0 \pm \mathrm{I} .4$ \\
$C_{\text {max }}\left(\mathrm{mg} \cdot \mathrm{L}^{-1}\right)$ & $210.2 \pm 32.2$ & $164.2 \pm 32.9$ \\
$t_{1 / 2}(\mathrm{~h})$ & $4.5 \pm \mathrm{I} .0$ & $3.3 \pm 0.3$ \\
$\mathrm{MRT}_{0 \rightarrow 12}(\mathrm{~h})$ & $5.8 \pm 0.6$ & $5.4 \pm 0.9$ \\
\hline
\end{tabular}

Notes: $* P<0.05$ versus BJO-E treated rats as the control. $(\mathrm{n}=6, \bar{x} \pm \mathrm{s}$ ).

Abbreviations: BJO-CN, Brucea javanica oil cationic nanoemulsions; BJO-E, Brucea javanica oil emulsion; $\mathrm{AUC}_{0 \rightarrow 12}$, area under the curve from 0 to the 12th hour; $\mathrm{AUC}_{0 \rightarrow \infty}$, area under the curve during the whole time; $T_{\text {max }}$, time of maximum concentration; $C_{\max }$, maximum concentration; $t_{1 / 2}$, half-life of elimination; $M R T_{0 \rightarrow 12}$, mean residue time; s, standard deviation.

day 18 (as shown in Figure 7), confirming that the orthotopic transplantation model of human lung adenocarcinoma line A549 cells in nude mice was successfully constructed.

\section{Determination of antitumor effect}

Median survival time and weight of lung tissues with tumor

The survival curves are shown in Figure 8, and the median survival time (MST) is listed in Table 3. Results indicated that the MST of nude mice in the model group was 27 days and that in the positive group, combination group, test group, and reference group, it was $46,61,44$, and 46 days, respectively. Compared with the model group, the MST of nude mice in all treatment groups was prolonged, with the mice in the combination group having significantly extended survival. The treatment effect among the other three groups was similar. The photographs of lung tissues with tumor in all groups are shown in Figure 9, and the weight of lung tissues is listed in Table 4. Compared with the model group, the weight of lung tissues with tumor in all the treatment groups decreased, and there was significant difference between model group and all the treatment groups. Besides, the weight of lung tissues with tumor in the positive group and the combination group was
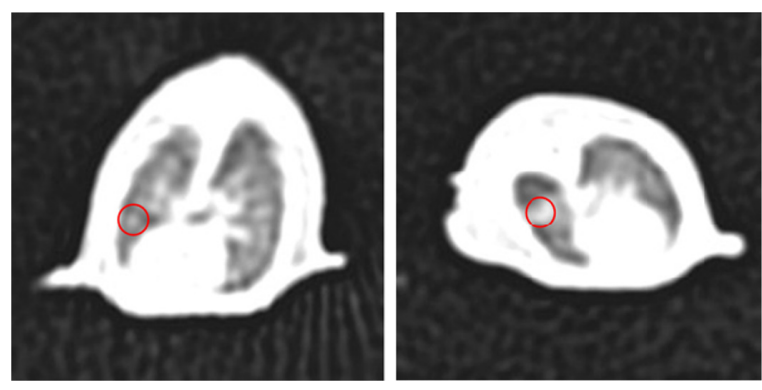

Figure $7 \mathrm{CT}$ image of lung tissues in cancer-bearing nude mice.

Note: The red circles indicate the tumor.

Abbreviation: CT, computed tomography. 


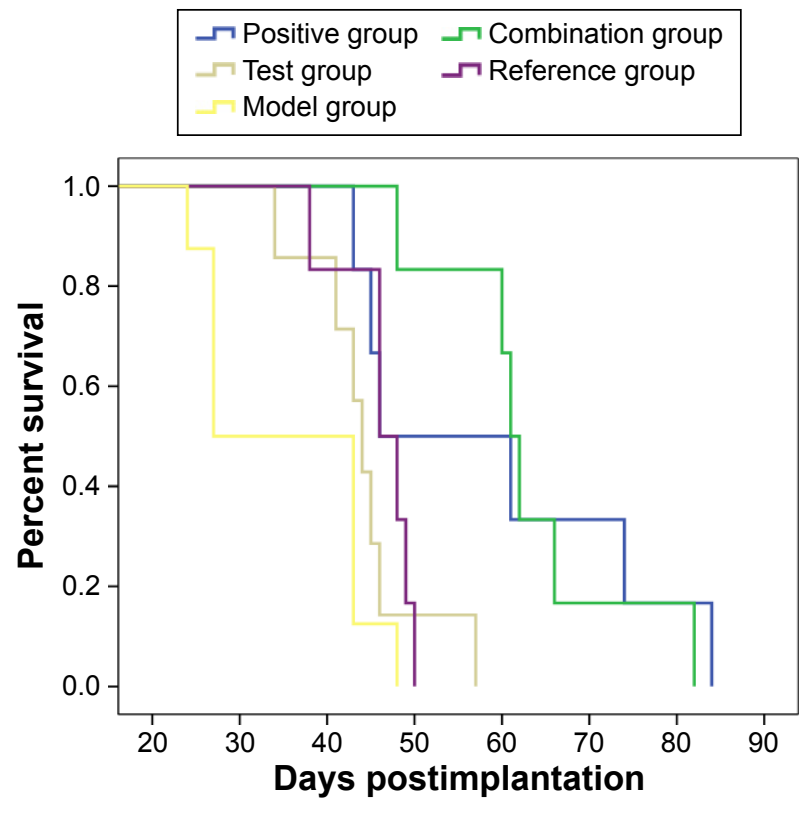

Figure 8 Survival curves of nude mice after oral administration in all the groups: positive, combination, test, reference, and model group.

smaller than that in the reference group and the test group, but there was no significant difference between both of them. These results implied that, compared with BJO-E, although the drug content of BJO-CN was reduced to half, its treatment effect was similar in terms of prolonging survival and inhibiting tumor growth. Nude mice in the combination group survived better than those in all the other treatment groups, demonstrating a synergistic effect of $\mathrm{VbT}$ and BJO-CN. The possible reason was that vinorelbine was a cell cycle-specific anticancer drug, whereas BJO was a cell cycle-nonspecific anticancer drug; therefore, the two different mechanisms may improve the combined efficacy. ${ }^{10,17}$ In addition, $\mathrm{VbT}$ was given for 4 weeks in the experiment, which may induce drug resistance, but $\mathrm{BJO}$ had the effect of reversing multidrug resistance of tumor cells, ${ }^{13,14}$ thereby enhancing the efficacy of combination group.

\section{HE staining}

HE-stained slice of tumor tissue was placed under a light microscope and magnified 100 and 400 times to observe

Table 3 Median survival time of nude mice in all the groups

\begin{tabular}{ll}
\hline Group & Median survival time (day) \\
\hline Model & 27 \\
Positive & 46 \\
Combination & 61 \\
Test & 44 \\
Reference & 46 \\
\hline
\end{tabular}

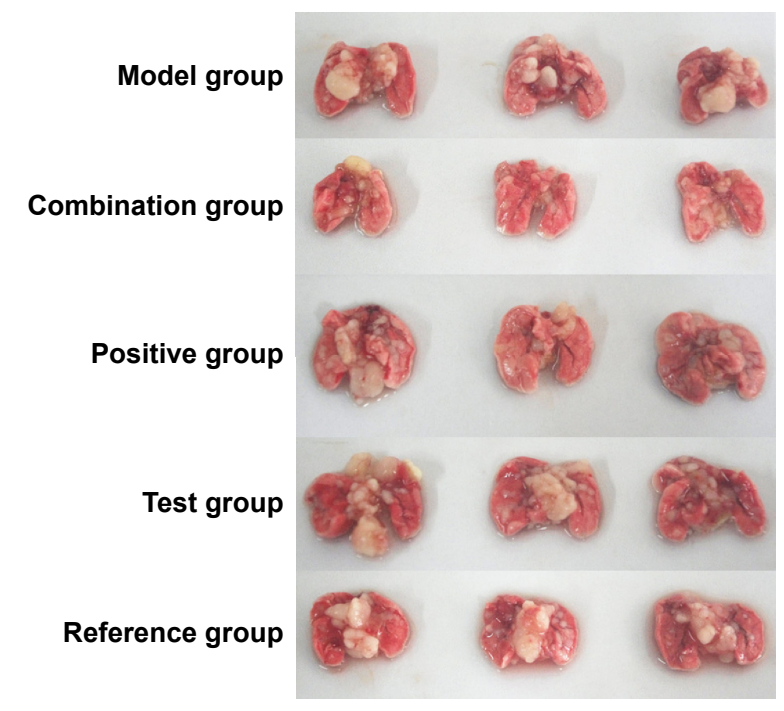

Figure 9 Pictures of lung tissues with tumor after oral administration in all the groups: positive, combination, test, reference, and model group.

Note: The white block that appeared in the lungs was tumor tissue, and its visual volume was helpful to judge the growth of tumor.

pathological changes of tumor tissue (as shown in Figures 10 and 11, respectively). Cancer cells had larger nucleus, less cytoplasm and abnormal nucleus pulp, and was stained deeper. Tumor cells in the model group arranged closely and showed pleomorphism and hyperchromatism. Compared with the model group, cancer cells in other treatment groups exhibited sparse arrangement and wide cell space, and there was no significant cell necrosis in lung tissues.

\section{Immunohistochemistry}

In this experiment, we selected four IHC indicators, VEGF, IL-8, Bcl-2, and P53, to further investigate the antitumor effect of BJO. The four indicators have been researched in depth, and their functions in the process of tumor growth have been confirmed.

Angiogenesis is closely related to the proliferation of tumor cells, and the role of VEGF in tumor angiogenesis has been extensively studied, confirming that VEGF has closely

Table 4 Weight of lung tissues with tumor in nude mice of all the groups

\begin{tabular}{llllllll}
\hline Group & \multicolumn{6}{c}{ Weight of lung tissues with tumor $(\mathbf{g})$} \\
\cline { 2 - 8 } & $\mathbf{I}$ & $\mathbf{2}$ & $\mathbf{3}$ & $\mathbf{4}$ & $\mathbf{5}$ & $\mathbf{6}$ & Mean \pm SD \\
\hline Model & 0.454 & 0.682 & 0.682 & 0.410 & 0.350 & 0.406 & $0.497 \pm 0.147$ \\
Positive & 0.311 & 0.221 & 0.267 & 0.327 & 0.200 & 0.264 & $0.265 \pm 0.049 *$ \\
Combination & 0.314 & 0.270 & 0.323 & 0.230 & 0.301 & 0.168 & $0.268 \pm 0.059^{*}$ \\
Test & 0.344 & 0.289 & 0.301 & 0.321 & 0.315 & 0.297 & $0.311 \pm 0.020^{*}$ \\
Reference & 0.455 & 0.332 & 0.366 & 0.320 & 0.357 & 0.379 & $0.368 \pm 0.048^{*}$ \\
\hline
\end{tabular}

Note: $* P<0.05$ versus model group as the control.

Abbreviation: SD, standard deviation. 

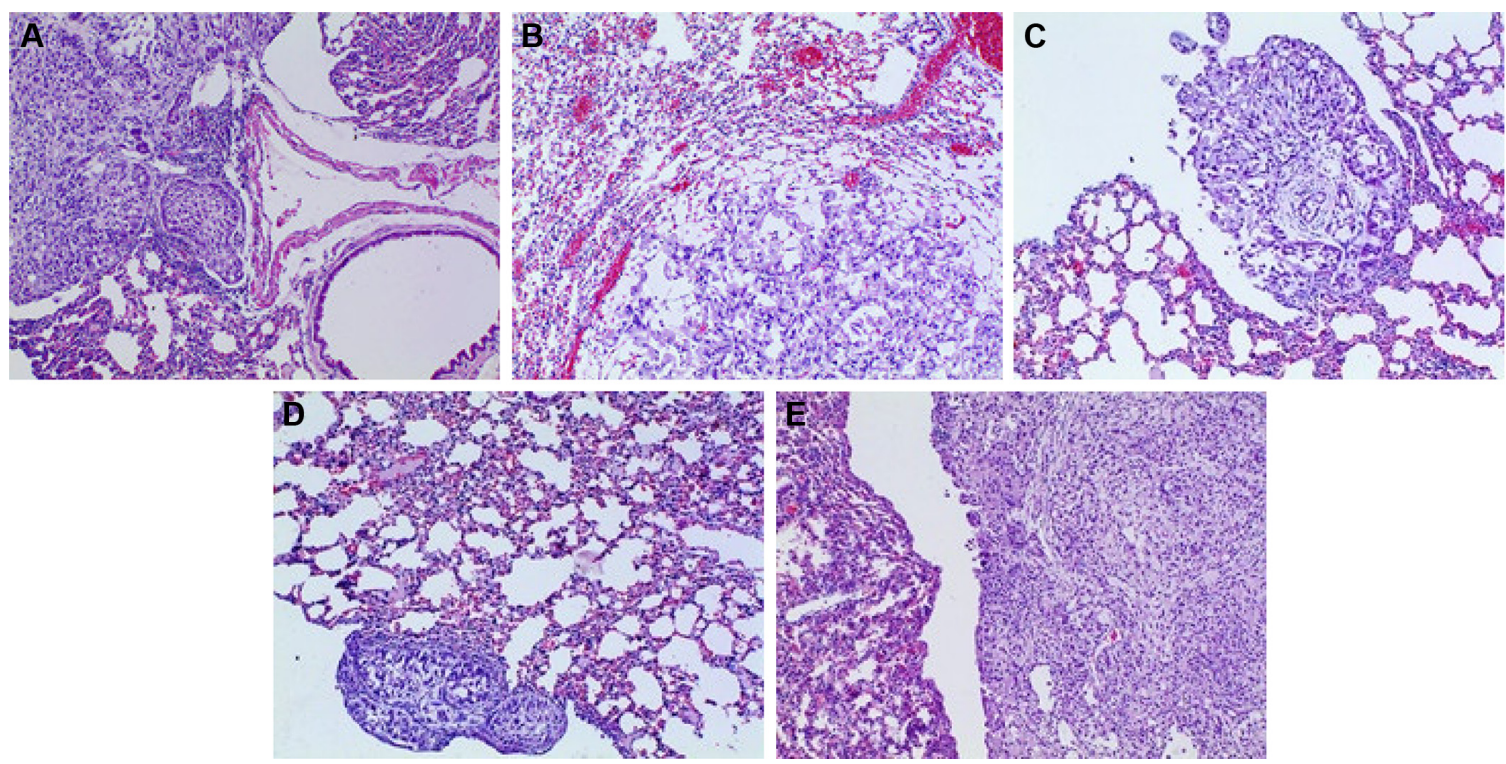

Figure 10 Pathomorphological changes of A549 tumor section in all the groups $(\times 100)$.

Notes: (A) Positive group, (B) combination group, (C) test group, (D) reference group, and (E) model group.

associated with the development of various types of tumors. ${ }^{47}$ VEGF is capable of binding to receptor tyrosine kinase (RTK), so it can activate the RTK on the endothelial cell surface, thereby promoting the proliferation of endothelial cells and participating in angiogenesis. ${ }^{48}$ Studies have shown that tumor cells can secrete VEGF through autocrine modes to promote its own growth by binding to VEGF receptor and can also secrete VEGF through paracrine modes to provide nutrients and oxygen for further tumor growth by inducing the formation of new blood vessels; therefore, VEGF plays a central role in tumor formation, growth, and metastasis process. Because
VEGF is highly expressed in non-small-cell lung cancer and is closely related to the prognosis of patients with non-small-cell lung cancer, inhibiting its expression and secretion in tumor tissues could be used for therapeutic purpose. ${ }^{49}$

IL-8 was initially thought to be an inflammatory cytokine that could induce activation and chemotaxis of neutrophils, playing an important role in the regulation of immunity and inflammation. In 1992, Strieter et $\mathrm{al}^{50}$ found that IL-8 could promote corneal neovascularization in rabbits. Afterward, the function of IL-8 in tumor development received comprehensive attention, and its effect on promoting tumor angiogenesis was
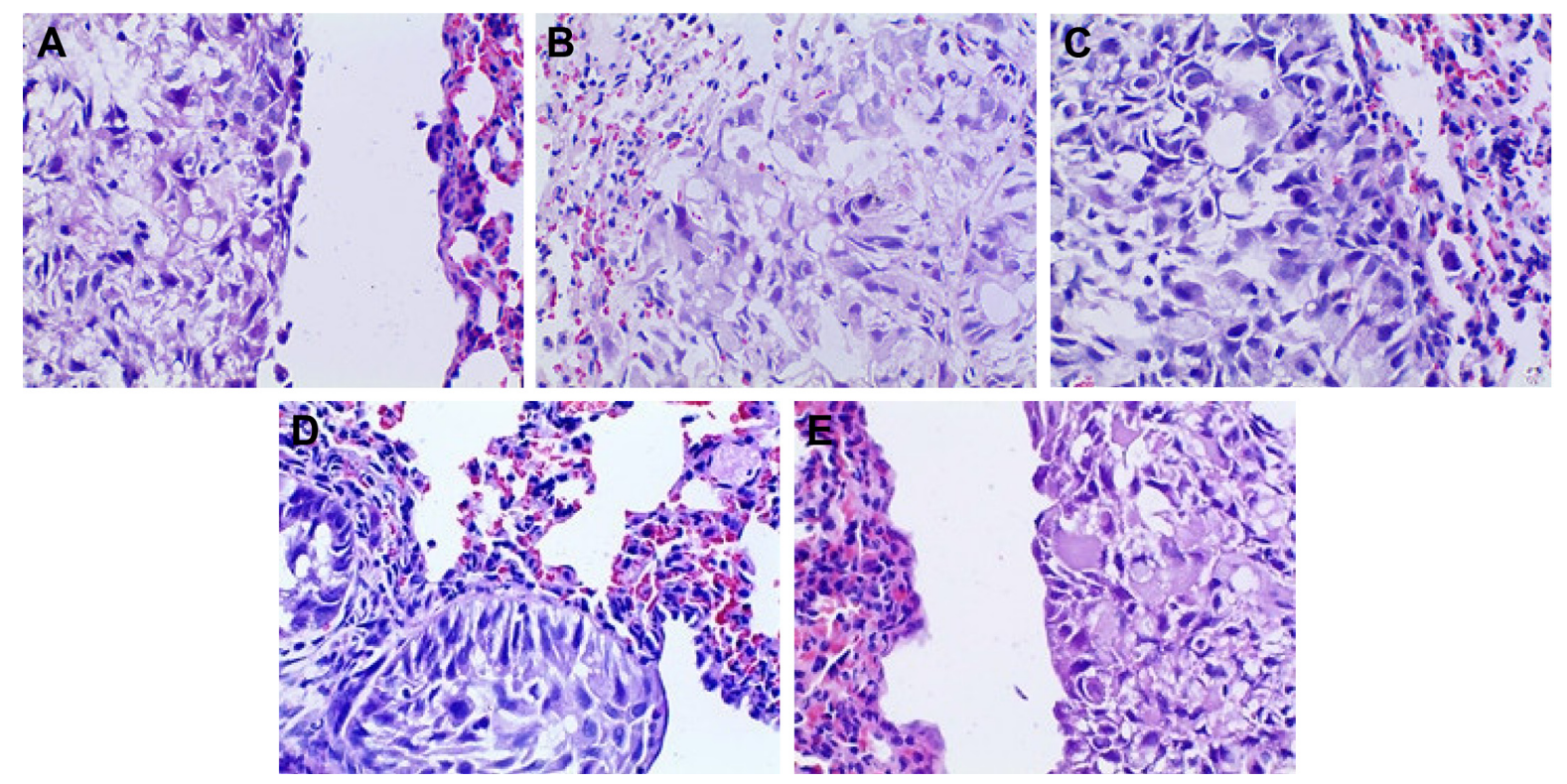

Figure I I Pathomorphological changes of A549 tumor section in all the groups $(\times 400)$.

Notes: (A) Positive group, (B) combination group, (C) test group, (D) reference group, and (E) model group. 
confirmed. The results of many studies have demonstrated increased levels of IL-8 expression in various tumor tissues, such as lung cancer, ${ }^{51}$ colorectal cancer, ${ }^{52}$ gastric,${ }^{53}$ breast cancer. ${ }^{54}$ Arenberg et al's ${ }^{55}$ study confirmed that inhibiting the expression of IL-8 in SCID mice could reduce the incidence of non-small-cell lung cancer. High expression of IL-8 is closely related to the development of non-small-cell lung cancer; therefore, IL- 8 can be used as a biochemical indicator for patients with non-small-cell lung cancer after prognosis. ${ }^{56,57}$

$B c l-2$ gene is a proto-oncogene, and the $B c l-2$ gene family plays an important role in the regulation of apoptosis. $\mathrm{Bcl}-2$ gene family consists of an antiapoptotic protein subfamily (such as Bcl-2 proteins) and a proapoptotic protein subfamily (such as Bax proteins), among which the mechanism of Bcl-2 family proteins has received more attention. The antiapoptotic protein $\mathrm{Bcl}-2$ can stabilize mitochondrial membrane and hinder cytochrome-C release into the cytoplasm, thereby impeding cell apoptosis. As reported in the literature, inhibiting the expression of antiapoptotic protein Bcl-2 could promote apoptosis of cancer cells. ${ }^{58,59}$ However, the prognostic significance of overexpression of $\mathrm{Bcl}-2$ protein for cancer patients was not uniform. It was thought that the overexpression of $\mathrm{Bcl}-2$ protein showed no significant correlation with patient prognosis in some studies, ${ }^{60}$ but some other studies showed that it was related with good prognosis for cancer patients. ${ }^{61}$

P53 gene is one of the important tumor suppressor genes that plays an important role in the regulation of apoptosis. Studies have confirmed that $P 53$ genes consist of wild-type P53 gene and mutant-type P53 gene. Wild-type P53 gene could induce tumor apoptosis, but mutant-type $P 53$ gene could catalyze tumor growth as a cancer gene. ${ }^{62}$ It has been reported that wild-type $\mathrm{P} 53$ protein can be degraded quickly, with short half-life in the cell; so, its content may be beyond the detection limit of IHC technique. In contrast, mutant P53 protein has good stability and can be accumulated in the nucleus with half-life prolonged by 20 times; thus, it is easy to be detected by the IHC technique. ${ }^{63}$ However, some studies have indicated that the mutation rate of $P 53$ gene was usually lower than the expression rate of P53 protein ${ }^{64}$ and that DNA damage could lead to expression of wild-type P53 protein; therefore, wild-type P53 protein can be detected by the IHC technique. ${ }^{65,66}$ The results of this experiment suggested that $\mathrm{p} 53$ protein in the orthotopic mouse model of human lung adenocarcinoma A549 cells was upregulated after drug treatment. Here, it must be noted that p53 antibody used in the study did not discriminate between wild-type $\mathrm{p} 53$ protein and mutant-type $\mathrm{p} 53$ protein and that the p53 gene in A549 cells was wild-type. In addition, considering that the experiment did not involve other carcinogens or cancer-causing conditions, we doubt if the positive expression in the IHC test was the wild-type $\mathrm{p} 53$ protein, and this needs to be further verified by the Western blot, reverse transcriptionpolymerase chain reaction, and gene mutation detection.

The positive IHC staining of VEGF, IL-8, Bcl-2, and P53 showed brownish particle deposition in the cytoplasm, organelles, and nucleus of cancer cells (as presented in Figures 12-15), and the optical density values calculated for the four indicators are summarized in Table 5. From the results, we inferred that, compared with model group, the combination

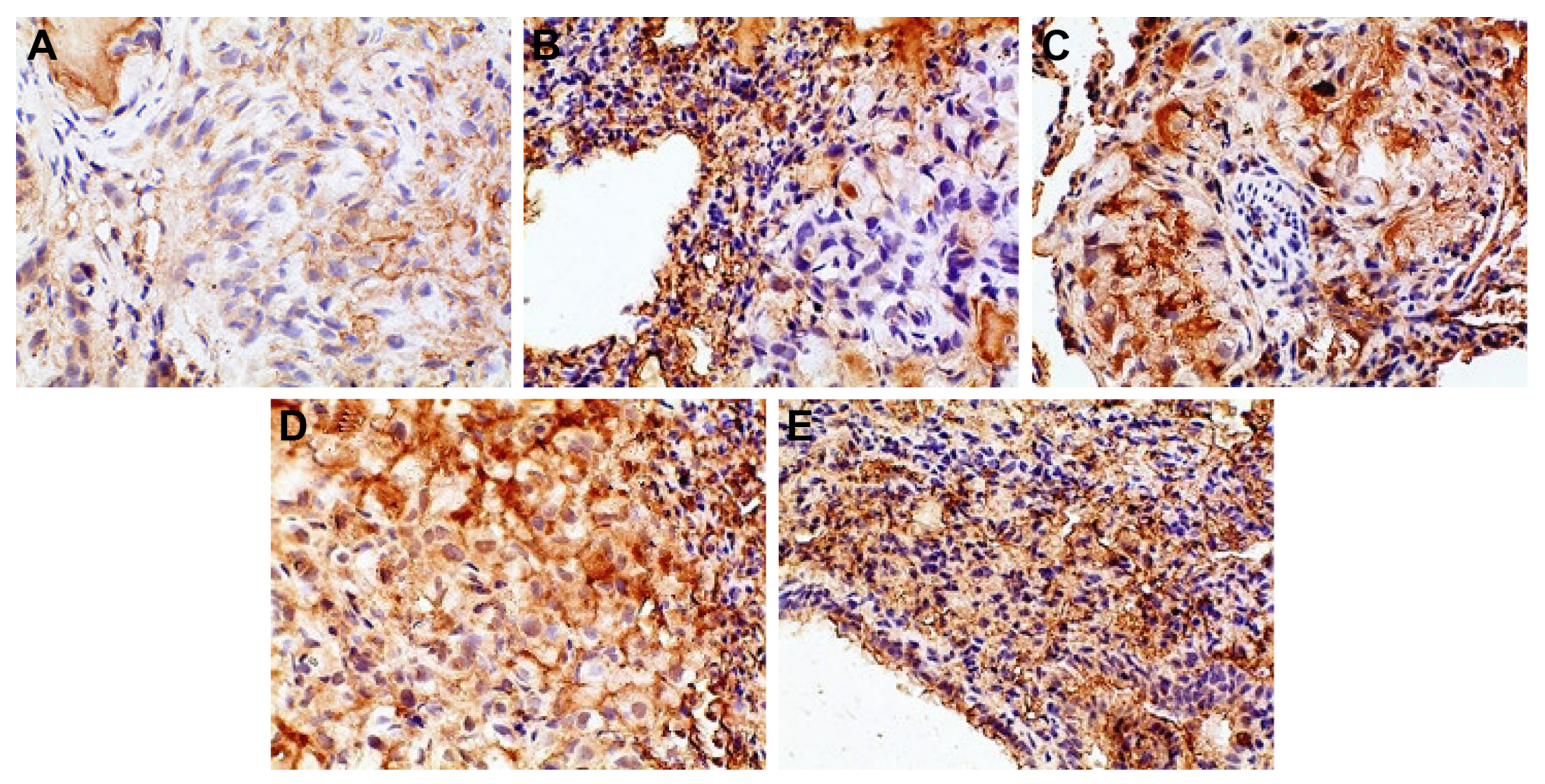

Figure 12 Immunohistochemical staining for VEGF of orthotopic tumors in all the groups.

Notes: (A) Positive group, (B) combination group, (C) test group, (D) reference group, and (E) model group. Magnification $\times 400$.

Abbreviation: VEGF, vascular endothelial growth factor. 


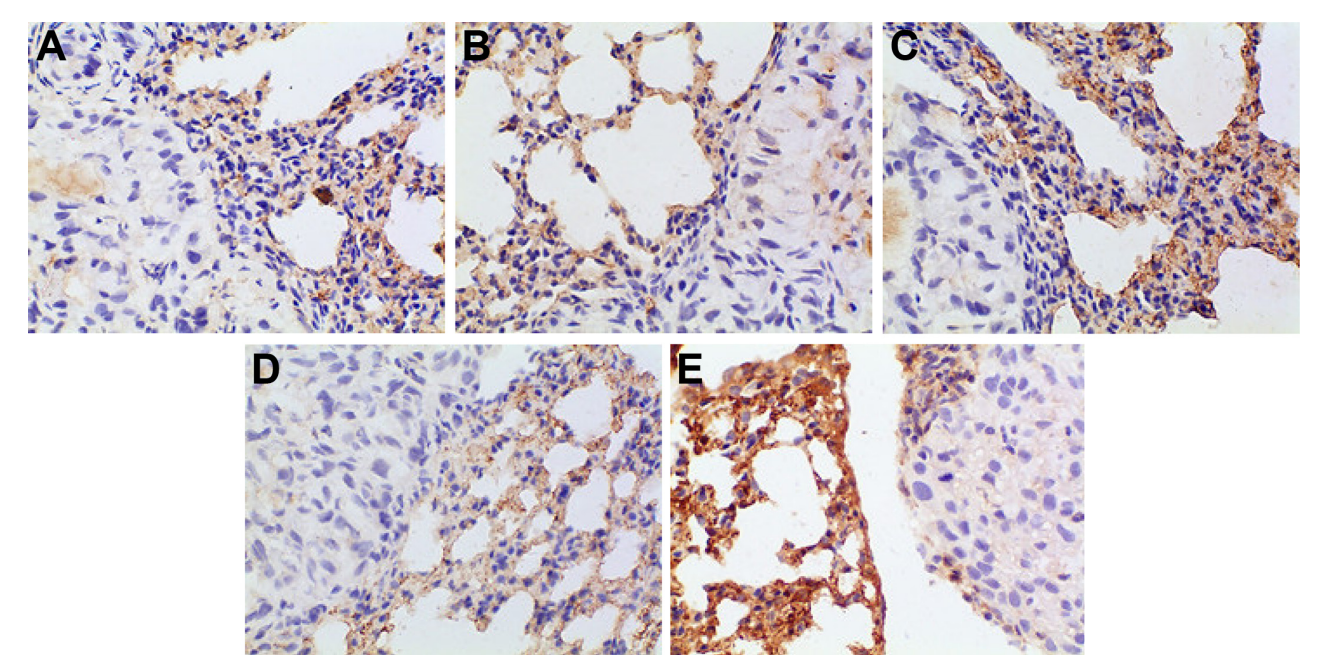

Figure 13 Immunohistochemical staining for IL-8 of orthotopic tumors in all the groups.

Notes: (A) Positive group, (B) combination group, (C) test group, (D) reference group, and (E) model group. Magnification $\times 400$ Abbreviation: IL, interleukin.
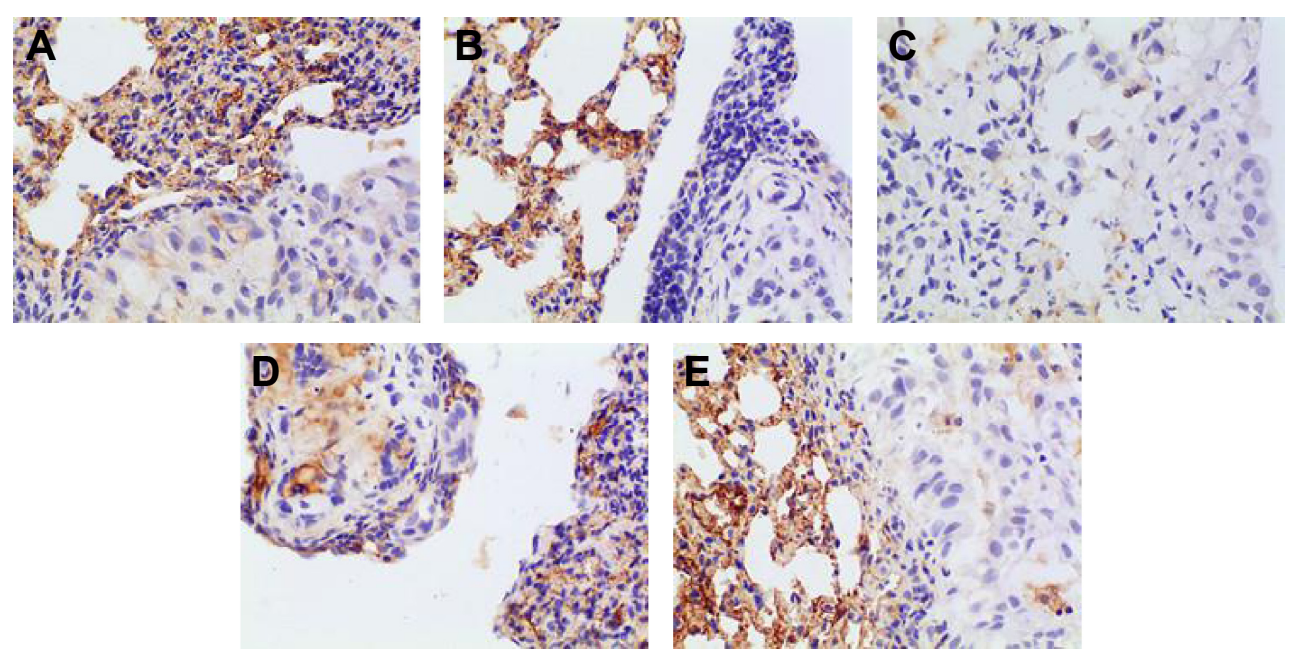

Figure 14 Immunohistochemical staining for $\mathrm{Bcl}-2$ of orthotopic tumors in all the groups.

Notes: (A) Positive group, (B) combination group, (C) test group, (D) reference group, and (E) model group. Magnification $\times 400$. Abbreviation: Bcl-2, B-cell lymphoma-2.

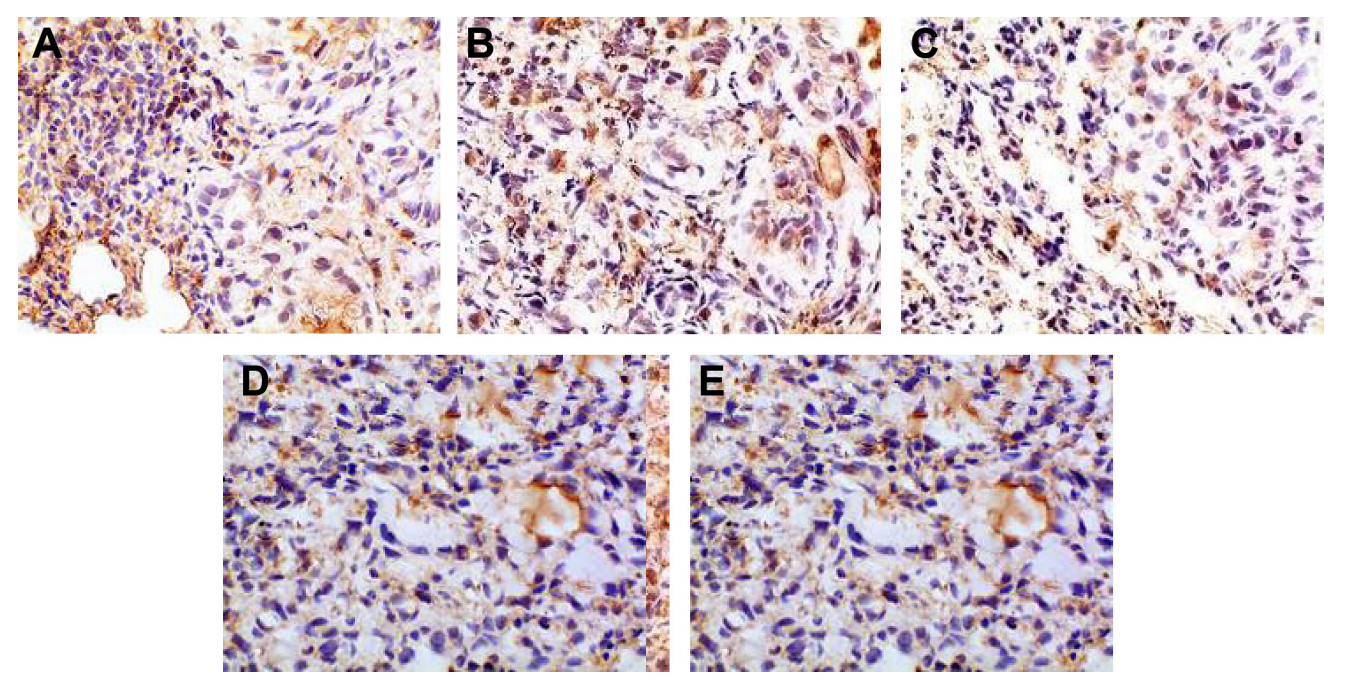

Figure 15 Immunohistochemical staining for P53 of orthotopic tumors in all the groups.

Notes: (A) Positive group, (B) combination group, (C) test group, (D) reference group, and (E) model group. Magnification $\times 400$. 
Table 5 Mean IOD of VEGF-/IL-8-/Bcl-2-/P53-positive area in tumor tissues

\begin{tabular}{lllll}
\hline Group & \multicolumn{4}{l}{ Mean IOD of positive area } \\
\cline { 2 - 5 } & VEGF & IL-8 & Bcl-2 & P53 \\
\hline Model & $0.265 \pm 0.086$ & $0.106 \pm 0.043$ & $0.090 \pm 0.046$ & $0.065 \pm 0.018$ \\
Positive & $0.173 \pm 0.124$ & $0.057 \pm 0.036$ & $0.045 \pm 0.008$ & $0.128 \pm 0.054$ \\
Combination & $0.180 \pm 0.057$ & $0.049 \pm 0.029 *$ & $0.044 \pm 0.018^{*}$ & $0.231 \pm 0.064^{*}$ \\
Test & $0.194 \pm 0.074$ & $0.092 \pm 0.041$ & $0.063 \pm 0.038$ & $0.124 \pm 0.072$ \\
Reference & $0.236 \pm 0.111$ & $0.060 \pm 0.010$ & $0.064 \pm 0.023$ & $0.142 \pm 0.08$ I \\
\hline
\end{tabular}

Note: $* P<0.005$ versus model group as the control.

Abbreviations: IOD, integrated optical density; VEGF, vascular endothelial growth factor; IL-8, interleukin-8; Bcl-2, B-cell lymphoma-2.

group had lower mean IOD of VEGF, the lowest mean IOD of IL- 8 and Bcl-2, and the highest mean IOD of P53 in the positive expression area, showing statistical significance $(P<0.005)$, confirming its best antitumor effect achieved by the mechanisms mentioned previously. Besides, compared with the positive group and the test group, in the combination group VEGF, IL-8, and Bcl-2 were downregulated and P53 was upregulated to a greater extent, demonstrating the superiority of BJO as an adjuvant therapy. Similarly, when BJO-CN and BJO-E were compared, we found that the regulating effect of BJO-CN on VEGF and Bcl-2 was greater than that of BJO-E, whereas the regulating effect of BJO-CN on IL-8 and P53 was less than that of BJO-E, revealing that the comprehensive regulating effect of $\mathrm{BJO}-\mathrm{CN}$ on antitumor indicators was comparable with that of BJO-E, even in the case of reducing the dose by half. Combined with the pharmacokinetic results, we speculated that it was closely related with the increased oral bioavailability of BJO-CN. In addition, BJO is a mixed fatty oil, and so the impact of each ingredient on antitumor effect and whether all the ingredients interact with each other are unclear. Therefore, we tentatively put forward that except for the dosage factor, BJO might be metabolized to different substances with different amounts and then influence related antitumor indicators to different extents. Nevertheless, concrete antitumor mechanism of BJO still needs to be verified.

\section{Conclusion}

In this study, BJO-CN were successfully prepared and comprehensively studied for its characteristics of optimization, providing reference for the development of cationic nanoemulsions. Pharmacokinetic results indicated that, compared with commercial BJO-E, oral bioavailability of BJO-CN was increased by 1.6-fold when using cationic nanoemulsions as the drug carrier. Afterward, we successfully established the orthotopic xenografts model of human lung adenocarcinoma cell line A549 in nude mice to study the antitumor effect of BJO-CN. Pharmacodynamic results revealed that even when the dosage in the BJO-CN group was half that in the BJO-E group, the inhibition effect of BJO-CN on lung cancer was comparable with BJO-E, confirming that cationic nanoemulsions significantly improved the antitumor effect of BJO. Moreover, the combined treatment of $\mathrm{VbT}$ and $\mathrm{BJO}-\mathrm{CN}$ in tumor-bearing nude mice was superior to that of $\mathrm{VbT}$ used alone, suggesting that $\mathrm{BJO}-\mathrm{CN}$ exhibited a synergistic effect with the first-line antitumor drug. In summary, the current work demonstrated that BJO-CN represent a promising chemotherapeutic system for enhancing the anticancer efficacy of both BJO itself and the combined first-line antitumor drugs, and contributed to decreasing the dose of BJO.

\section{Disclosure}

The authors report no conflicts of interest in this work.

\section{References}

1. Shi XP, Zhao HR. [Research progress of Brucea javanica oil]. Northwest Pharm J. 2010;25(3):240-242. Chinese.

2. Chen MW, Chen R, Wang SP, et al. Chemical components, pharmacological properties, and nanoparticulate delivery systems of Brucea javanica. Int J Nanomedicine. 2013;8:85-92.

3. Cui Y, Wu Z, Liu X, et al. Preparation, safety, pharmacokinetics, and pharmacodynamics of liposomes containing Brucea javanica oil. AAPS PharmSciTech. 2010;11(2):878-884.

4. Lin HY, Wu JM, Zhang WS. [Research progress of Brucea javanica oil]. Chin J Exp Tradit Med Formulae. 2006;12(4):65-69. Chinese.

5. Li JM. [Stability experiment of Brucea javanica oil oral liquid]. Shaanxi J Tradit Chin Med. 2006;27(2):231-232. Chinese.

6. Pan L, Chin YW, Chai HB, et al. Bioactivity-guided isolation of cytotoxic constituents of Brucea javanica collected in Vietnam. Bioorg Med Chem. 2009;17(6):2219-2224.

7. Han FJ, Cai DY, Wu XK, et al. [Research progress on antitumor mechanism of Brucea javanica oil emulsion]. J Mod Oncol. 2013;21(3): 669-671. Chinese.

8. Ma L, Zhang YN. [Effects of seminal oil emulsion of Brucea javanica on apoptosis and apoptosis-related genes in human hepatocellular carcinoma cells]. World Chin J Digestol. 2004;12(3):559-562. Chinese.

9. Li Y, Li Y, Zhang LY, et al. [Experimental study of Brucea javanica oil emulsion induces K562 cell apoptosis and its mechanism]. J Int Oncol. 2006;33(8):637-639. Chinese.

10. Zhang XJ, Wang XL, Zhao F, et al. [Inhibitory effect of Brucea javanica oil emulsion on proliferation of NCI-H460 cells and underlying mechanism]. Chin J Cancer Biother. 2011;18(5):519-523. Chinese.

11. Lou GG, Yao HP, Xie LP. Brucea javanica oil induces apoptosis in T24 bladder cancer cells via upregulation of caspase-3, caspase-9, and inhibition of NF-кB and COX-2 expressions. Am J Chin Med. 2010; 38(3):613-624.

12. Zhang H, Yang JY, Zhou F, et al. Seed oil of Brucea javanica induces apoptotic death of acute myeloid leukemia cells via both the death receptors and the mitochondrial-related pathways. Evid Based Complement Alternat Med. 2011;(5):1-14.

13. Gao N, Ru JQ, Zhang Y. [Research progress of Chinese traditional medicine reverse multidrug resistance in leukemia]. Jiangsu J Tradit Chin Med. 2007;39(3):60-62. Chinese.

14. Yu LF, Wu YL, Zhang YP. [Reversal of drug resistance in the vincristine-resistant human gastric cancer cell lines MKN28/VCR by emulsion of seminal oil of Brucea Javanica]. World Chin J Digestol. 2001 9(4):376-378. Chinese.

15. Wang HY, Yu GY, Cui J, et al. [Effect of Brucea javanica oil injection combined with chemotherapy on the immune function of patients with advanced lung cancer]. Mod J Integr Tradit Chin Western Med. 2006;15(5):586-587. Chinese. 
16. Guo RY, Li GQ. [Progress of Brucea javanica oil emulsion in clinical application]. Med J Chin People's Health. 2008;20(10):1066-1068. Chinese.

17. Tang XL, Tang M. [Research progress of Brucea javanica oil emulsion in patients with cancer]. World J Integr Tradit Western Med. 2013;8(4):430-432. Chinese.

18. Wang AR, Xu HY, Tang ZX, et al. [Effect of Brucea javanica oil emulsion injection in patients with malignant tumor on III-IV stage]. Mod J of Integr Tradit Chin Western Med. 2008;17(16):2514. Chinese.

19. Zhao BY, Fang M. [Clinical observation of Brucea javanica oil injection combined with EP regimen in the treatment of advanced non-small cell lung cancer]. J Clin Pulm Med. 2010;15(9):1233-1234. Chinese.

20. Ren YH, Liu HY, Quan WT. [Effect of Fructus Brucea oil emulsion combined with chemotherapy of NP regimen in patients with advanced NSCLC]. Prog Mod Biomed. 2012;12(21):4079-4082. Chinese.

21. Du F, Wang DL, Cao YJ, et al. [Effect of Brucea javanica oil emulsion combined with chemotherapy in patients with advanced non-small cell lung cancer]. Clin J Chin Med. 2015;7(36):139-140. Chinese.

22. Wang Q, Wang MC, He XR, et al. [Meta analysis of Brucea javanica oil emulsion combined with platinum based first-line chemotherapy in patients with non-small cell lung cancer]. China J Chin Materia Medica. 2012;37(13):2022-2029. Chinese.

23. Lawrence MJ, Rees GD. Microemulsion-based media as novel drug delivery systems. Adv Drug Deliv Rev. 2000;45(1):89-121.

24. Ogawa S, Decker EA, Mcclements DJ. Production and characterization of $\mathrm{O} / \mathrm{W}$ emulsions containing cationic droplets stabilized by lecithinchitosan membranes. J Agric Food Chem. 2003;51(9):2806-2812.

25. Anton N, Vandamme TF. Nano-emulsions and micro-emulsions: clarifications of the critical differences. Pharm Res. 2011;28(5):978-985.

26. Hagigit T, Abdulrazik M, Orucov F, et al. Topical and intravitreous administration of cationic nanoemulsions to deliver antisense oligonucleotides directed towards VEGF KDR receptors to the eye. $J$ Control Release. 2010;145(3):297-305.

27. Guo XX, Liu XY. [Study on the transdermal permeation enhancemant of N-trimenthly chitosan on beclomethasome dipropionate gels in vitro]. Chin Pharmacist. 2009;12(11):1523-1525. Chinese.

28. Yuki T, Haratake A, Koishikawa H, Morita K, Miyachi Y, Inoue S. Tight junction proteins in keratinocytes: localization and contribution to barrier function. Exp Dermatol. 2007;16(4):324-330.

29. Lallemand F, Daull P, Benita S, et al. Successfully improving ocular drug delivery using the cationic nanoemulsion, novasorb. J Drug Deliv. 2012;2012:1-16.

30. Jain V, Prasad V, Jadhav P, Mishra PR. Preparation and performance evaluation of saquinavir laden cationic submicron emulsions. Drug Deliv. 2009;16(1):37-44.

31. Liao D, Liu X, Dai W, et al. $N$-trimethyl chitosan (TMC)-modified microemulsions for improved oral bioavailability of puerarin: preparation and evaluation. Drug Deliv. 2014;22(4):1-6.

32. Larsson M, Huang W, Hsiao M, et al. Biomedical applications and colloidal properties of amphiphilically modified chitosan hybrids. Prog Polym Sci. 2013;38(9):1307-1328.

33. Wang JJ, Zeng ZW, Xiao RZ, et al. Recent advances of chitosan nanoparticles as drug carriers. Int J Nanomedicine. 2011;6:765-774.

34. Kean T, Roth S, Thanou M. Trimethylated chitosans as non-viral gene delivery vectors: cytotoxicity and transfection efficiency. $J$ Control Release. 2005;103(3):643-653.

35. Turner JR, Buschmann MM, Romero-Calvo I, Sailer A, Shen L. The role of molecular remodeling in differential regulation of tight junction permeability. Semin Cell Dev Biol. 2014;36:204-212.

36. Amor VM, Ibáñez de Cáceres, Bandres E, et al. DUSP1/MKP1 promotes angiogenesis, invasion and metastasis in non-small-cell lung cancer. Oncogene. 2011;30:668-678.

37. Im GH, Jang MS, Chung JJ, et al. Improvement of orthotopic lung cancer mouse model via thoracotomy and orotracheal intubation enabling in vivo imaging studies. Lab Anim. 2014;48(2):124-131.

38. Isobe T, Onn A, Morgensztern D, et al. Evaluation of novel orthotopic nude mouse models for human small-cell lung cancer. J Thorac Oncol. $2013 ; 8: 140-146$.
39. Jacoby JJ, Erez B, Korshunova MV, et al. Treatment with HIF-1 $\alpha$ antagonist PX-478 inhibits progression and spread of orthotopic human small cell lung cancer and lung adenocarcinoma in mice. $J$ Thorac Oncol. 2010;5(7):940-949.

40. Luo SW, Deng YH, Zhu YH. [Determination of Oleic Acid and Linoleic Acid in the Oil of Fructus Bruceae by Pre-column Derivatization HPLC]. Traditional Chinese Drug Research and Clinical Pharmacology. 2011;22(3):328-330. Chinese.

41. Ding Y, Tang X. [Determination of fatty acids in Fructus Bruceae oil by precolumn derivation HPLC]. Chinese Traditional and Herbal Drugs. 2004;35(9):988-991. Chinese.

42. Baspinar Y, Borchert H-H. Penetration and release studies of positively and negatively charged nanoemulsions - is there a benefit of the positive charge? Int J Pharm. 2012;43(1-2):247-252.

43. Yu H, Lopez E, Young SW, et al. Quantitative analysis of free fatty acids in rat plasma using matrix-assisted laser desorption/ionization time-offlight mass spectrometry with meso-tetrakis porphyrin as matrix. Anal Biochem. 2006;354:182-191.

44. McGarry JD, Dobbins RL. Fatty acids, lipotoxicity and insulin secretion. Diabetologia. 1999;42:128-138.

45. Hussain MM. Intestinal lipid absorption and lipoprotein formation. Curr Opin Lipidol. 2014;25:200-206.

46. Onn A, Isobe T, Itasaka S, et al. Development of an orthotopic model to study the biology and therapy of primary human lung cancer in nude mice. Clin Cancer Res. 2003;9:5532-5539.

47. Shinkaruk S, Bayle M, Lain G, Déléris G. Vascular endothelial cell growth factor (VEGF), an emerging target for cancer chemotherapy. Curr Med Chem Anticancer Agents. 2003;3(2):95-117.

48. Tas F, Duranyildiz D, Oguz H, Camlica H, Yasasever V, Topuz E. Serum vascular endothelial growth factor (VEGF) and bcl-2 levels in advanced stage non-small cell lung cancer. Cancer Invest. 2006;24(6):576-580.

49. Shibuya K, Komaki R, Shintani T, et al. Targeted therapy against VEGFR and EGFR with ZD6474 enhances the therapeutic efficacy of irradiation in an orthotopic model of human non-small cell lung cancer. Int J Radiat Oncol Biol Phys. 2007;69(5):1534-1543.

50. Strieter RM, Kunkel SL, Elner VM, et al. Interleukin-8 corneal factor that induces neovascularization. Am J Pathol. 1992;141(6):1279-1284.

51. Smith DR, Polverini PJ, Kunkel SL, et al. Inhibition of interleukin 8 attenuates angiogenesis in bronchogenic carcinoma. J Exp Med. 1994; 179(5):1409-1415.

52. Rubie C, Frick VO, Pfeil S, et al. Correlation of IL-8 with induction, progression and metastatic potential of colorectal cancer. World J Gastroenterol. 2007;13(37):4996-5002.

53. Lee KH, Bae SH, Lee JL, et al. Relationship between urokinase-type plasminogen receptor, interleukin-8 gene expression and clinicopathological features in gastric cancer. Oncology. 2004;66(3):210-217.

54. Fuksiewicz M, Kaminska J, Kotowicz B, Kowalska M, Rubach M, Pienkowski T. Serum cytokine levels and the expression of estrogen and progesterone receptors in breast cancer patients. Clin Chem Lab Med. 2006;44(9):1092-1097.

55. Arenberg DA, Kunkel SL, Polverini PJ, Glass M, Burdick MD, Strieter RM. Inhibition of interleukin-8 reduces tumorigenesis of human non-small cell lung cancer in SCID mice. J Clin Invest. 1996; 97(12):2792-2802.

56. Sanmamed MF, Carranza-Rua O, Alfaro C, et al. Serum interleukin- 8 reflects tumor burden and treatment response across malignancies of multiple tissue origins. Clin Cancer Res. 2014;20(22):5697-5707.

57. Zhang E, Feng X, Liu F, Zhang P, Liang J, Tang X. Roles of PI3K/Akt and c-Jun signaling pathways in human papillomavirus type 16 oncoproteininduced HIF-1a, VEGF, and IL-8 expression and in vitro angiogenesis in non-small cell lung cancer cells. PLoS One. 2014;9(7):1-13.

58. Zou Y, Qin X, Xiong H, Zhu F, Chen T, Wu H. Apoptosis of human non-small-cell lung cancer A549 cells triggered by evodiamine through MTDH-dependent signaling pathway. Tumour Biol. 2015;36(7): $5187-5193$

59. Godugu C, Patel AR, Doddapaneni R, Somagoni J, Singh M. Approaches to improve the oral bioavailability and effects of novel anticancer drugs berberine and betulinic acid. PLoS One. 2014;9(3):1-15. 
60. Kim T, Han W, Kim MK, et al. Predictive significance of P53, Ki-67, and Bcl-2 expression for pathologic complete response after neoadjuvant chemotherapy for triple-negative breast cancer. J Breast Cancer. 2015;18(1):16-21.

61. Fontanini G, Vignati S, Bigini D, et al. Bcl-2 protein: a prognostic factor inversely correlated to P53 in non-small-cell lung cancer. Br J Cancer. 1995;71:1003-1007.

62. Vogelstein B, Lane D, Levine AJ. Surfing the P53 network. Nature. 2000;408(6810):307-310.

63. Hickman ES, Moroni MC, Helin K. The role of P53 and pRB in apoptosis and cancer. Curr Opin Genet Dev. 2002;12(1):60-66.
64. Zhai YL, Nikaido T, Toki T, Shiozawa A, Orii A, Fujii S. Prognostic significance of bcl-2 expression in leiomyosarcoma of the uterus. Br J Cancer. 1999;80(10):1658-1664.

65. Midgley CA, Lane DP. P53 protein stability in tumour cells is not determined by mutation but is dependent on $\mathrm{Mdm} 2$ binding. Oncogene. 1997;15:1179-1189.

66. Wang YC, Lin RK, Tan YH, et al. Wild-type P53 over-expression and its correlation with MDM2 and p14ARF alterations: an alternative pathway to non-small-cell lung cancer. J Clin Oncol. 2005;23(1):154-164.
International Journal of Nanomedicine

\section{Publish your work in this journal}

The International Journal of Nanomedicine is an international, peerreviewed journal focusing on the application of nanotechnology in diagnostics, therapeutics, and drug delivery systems throughout the biomedical field. This journal is indexed on PubMed Central, MedLine, CAS, SciSearch ${ }^{\circledR}$, Current Contents ${ } /$ Clinical Medicine,

\section{Dovepress}

Journal Citation Reports/Science Edition, EMBase, Scopus and the Elsevier Bibliographic databases. The manuscript management system is completely online and includes a very quick and fair peer-review system, which is all easy to use. Visit http://www.dovepress.com/ testimonials.php to read real quotes from published authors.

Submit your manuscript here: http://www.dovepress.com/international-journal-of-nanomedicine-journal 